\title{
Anti-Inflammatory Effect of Piper attenuatum Methanol Extract in LPS-Stimulated Inflammatory Responses
}

\author{
You Jin Kim, ${ }^{1}$ Jeong Deok, ${ }^{2}$ Sunggyu Kim, ${ }^{3}$ Deok Hyo Yoon, ${ }^{4}$ Gi-Ho Sung, \\ Adithan Aravinthan, ${ }^{5}$ Seungihm Lee, ${ }^{1}$ Mi-nam Lee, ${ }^{6}$ Suntaek Hong, ${ }^{7}$ Jong-Hoon Kim, ${ }^{5}$ \\ Young-Jin Son, ${ }^{8}$ and Jae Youl $\mathrm{Cho}^{2}$ \\ ${ }^{1}$ Gyeonggi Science High School for the Gifted, Suwon 16297, Republic of Korea \\ ${ }^{2}$ Department of Genetic Engineering, Sungkyunkwan University, Suwon 16419, Republic of Korea \\ ${ }^{3}$ Research and Business Foundation, Sungkyunkwan University, Suwon 16419, Republic of Korea \\ ${ }^{4}$ Institute for Bio-Medical Convergence, International St. Mary's Hospital and College of Medicine, \\ Catholic Kwandong University, Incheon, Republic of Korea \\ ${ }^{5}$ College of Veterinary Medicine, Chonbuk National University, Iksan 54596, Republic of Korea \\ ${ }^{6}$ Department of Food and Nutrition, Yeonsung University, Anyang 14011, Republic of Korea \\ ${ }^{7}$ Department of Biochemistry, Lee Gil Ya Cancer and Diabetes Institute, Gachon University, Incheon 21999, Republic of Korea \\ ${ }^{8}$ Department of Pharmacy, Sunchon National University, Suncheon 57922, Republic of Korea
}

Correspondence should be addressed to Jong-Hoon Kim; jhkim1@jbnu.ac.kr, Young-Jin Son; sony@sunchon.ac.kr, and Jae Youl Cho; jaecho@skku.edu

Received 1 April 2017; Revised 5 June 2017; Accepted 21 June 2017; Published 25 July 2017

Academic Editor: Olumayokun A. Olajide

Copyright (c) 2017 You Jin Kim et al. This is an open access article distributed under the Creative Commons Attribution License, which permits unrestricted use, distribution, and reproduction in any medium, provided the original work is properly cited.

Piper attenuatum is used as a traditional medicinal plant in India. One of the substances in P. attenuatum has been suggested to have anti-inflammatory effects. However, there is insufficient research about the anti-inflammatory mechanisms of action of $P$. attenuatum. The effects of $P$. attenuatum methanol extract (Pa-ME) on the production of inflammatory mediators nitric oxide $(\mathrm{NO})$ and prostaglandin $\mathrm{E}_{2}\left(\mathrm{PGE}_{2}\right)$, the expression of proinflammatory genes, the translocation level of transcription factors, and intracellular signaling activities were investigated using macrophages. Pa-ME suppressed the production of $\mathrm{NO}_{\text {and }} \mathrm{PGE} \mathrm{E}_{2}$ in lipopolysaccharide- (LPS-), pam3CSK4-, and poly(I:C)-stimulated RAW264.7 cells without displaying cytotoxicity. The mRNA expression levels of inducible NO synthase (iNOS) and cyclooxygenase 2 (COX-2) were decreased by Pa-ME. P-ME reduced the translocation of p50/NF- $\kappa$ B and AP-1 (c-Jun and c-Fos), as well as the activity of their upstream enzymes Src, Syk, and TAK1. Immunoprecipitation analysis showed failure of binding between their substrates, phospho- (p-) p85 and p-MKK3/6. p-p85 and $\mathrm{p}-\mathrm{MKK} 3 / 6$, which were induced by overexpression of Src, Syk, and TAK1, were also reduced by Pa-ME. Therefore, these results suggest that Pa-ME exerts its anti-inflammatory effects by targeting Src and Syk in the NF- $\kappa$ B signaling pathway and TAK1 in the AP-1 signaling pathway.

\section{Introduction}

Inflammation is a kind of innate immunity that provides a defense against pathogens, damaged cells, and other dangerous molecules. Inflammatory cells, such as macrophages and neutrophils, let leukocytes and plasma components come to sites where infection or injury has occurred during inflammation to eliminate dangers $[1,2]$. Although inflammation is important to the immune system, excessive activity of inflammatory cells can cause cancer, rheumatoid arthritis, multiple sclerosis, chronic asthma, psoriasis, and other diseases $[1,3,4]$. To treat those inflammation-driven diseases, inflammatory responses should be controlled. Nuclear factor(NF-) $\kappa \mathrm{B}$ and activator protein- (AP-) 1 are two main transcription factors that initiate inflammation by activation of a series of intracellular signals composed of inhibitor of 
$\kappa \mathrm{B}$ kinase $(\mathrm{IKK} \alpha / \beta)$, AKT (protein kinase B), Src, and Syk for NF- $\kappa \mathrm{B}$ and extracellular signal-regulated kinase (ERK), p38, c-Jun N-terminal kinase (JNK), interleukin-1 receptorassociated kinase 1 (IRAK1), IRAK4, transforming growth factor beta-kinase 1 (TAK1), mitogen-activated protein kinase kinase 3 (MKK3), and MKK6 for AP-1 [5-8]. These molecules are usually considered targets for suppression of the NF- $\kappa \mathrm{B}$ or AP-1 pathways to obtain anti-inflammatory outcomes.

Piper attenuatum is a plant in the Piperaceae family that inhabits the eastern tropical Himalayas, Assam, Khasi Hills, and the Nilgiris in India. The whole plant is used to cure headache and muscular pain [9]. Piper attenuatum has antibacterial [10] and antioxidant effects [11], and neolignans in $P$. attenuatum fruit are candidate free radical scavengers [12]. In addition, many substances such as cepharanone $\mathrm{B}$, piperolactam $\mathrm{A}$, piperolactam $\mathrm{D}$, and cepharadione $\mathrm{A}$ have been isolated from $P$. attenuatum [13]. Cepharanone and piperolactam exhibit anti-inflammatory effects [13]. However, there is no detailed research regarding the antiinflammatory mechanism of $P$. attenuatum. In this study, we aimed to explore the molecular mechanism of $P$. attenuatum with its methanol extract (Pa-ME) with respect to the NF- $\kappa \mathrm{B}$ and AP-1 signaling pathways.

\section{Materials and Methods}

2.1. Materials. Methanol extraction of P. attenuatum (PaME) was purchased from the Plant Extract Bank in the Plant Diversity Research Center (Daejeon, Republic of Korea; http:// extract.kribb.re.kr, e-mail: mplantext@kribb.re.kr). RAW264.7 cells, a transformed macrophage cell line derived from the $\mathrm{BALB} / \mathrm{c}$ mouse (ATCC number TIB-71), were purchased from ATCC (Rockville, MD, USA). Dimethyl sulfoxide (DMSO), L-N ${ }^{\mathrm{G}}$-nitroarginine methyl ester (L-NAME), indomethacin, lipopolysaccharide (LPS, Escherichia coli 0111:B4), pam3CSK, and (3-4,5-dimethylthiazol-2-yl)-2,5-diphenyltetrazolium bromide (MTT) were purchased from Sigma Chemical Co. (St Louis, MO, USA). Poly I:C was obtained from Calbiochem (La Jolla, CA). The enzyme immune assay (EIA) kits used to quantitate the levels of $\mathrm{PGE}_{2}$ were purchased from Amersham (Little Chalfont, Buckinghamshire, UK). Specific PCR primers for iNOS, TNF- $\alpha$, COX-2, and GAPDH were synthesized from Bioneer Inc. (Daejeon, Republic of Korea). Antibodies that specify phosphorylated and total forms of p65, p50, c-Jun, c-Fos, Lamin A/C, I $\kappa \mathrm{B} \alpha, \mathrm{IKK} \alpha / \beta, \mathrm{AKT}$, Src, Syk, ERK, p38, JNK, IRAK1, IRAK4, TAK1, MKK3/6, and $\beta$-actin were obtained from Cell Signaling (Beverly, MA, USA).

2.2. Animals. Male C57BL/6 mice (6-8 weeks old, 17-21 g) were obtained from DAEHAN BIOLINK (Chungbuk, Republic of Korea) and were housed in groups of 6-8 mice under a 12-hour light/dark cycle (lights on at 6 a.m.). Water and pellet diets (Samyang, Daejeon, Republic of Korea) were supplied ad libitum. Animals were cared for in accordance with the guidelines issued by the National Institute of Health for the Care and Use of Laboratory Animals (NIH Publication 80-23, revised in 1996). Studies were performed in accordance with guidelines established by the Institutional Animal Care and Use Committee at Sungkyunkwan University.

2.3. Preparation of Peritoneal Macrophages. To obtain peritoneal macrophages, we used C57BL/6 male mice lavaged 4 days after intraperitoneal injection of $1 \mathrm{ml}$ of sterile $4 \%$ thioglycollate broth (Difco Laboratories, Detroit, MI). Then, peritoneal macrophages $\left(1 \times 10^{6}\right.$ cells $\left./ \mathrm{ml}\right)$ were washed using RPMI1640 medium with 10\% FBS and were plated in $100 \mathrm{~mm}$ tissue culture dishes for $4 \mathrm{~h}$ at $37^{\circ} \mathrm{C}$ in $5 \% \mathrm{CO}_{2}$ in a humidified incubator.

2.4. Cell Culture. RAW264.7 cells, HEK293 cells, and peritoneal macrophages were cultured or maintained in RPMI1640 medium with $10 \%$ heat-inactivated FBS, $2 \mathrm{mM}$ of L-glutamine, and antibiotics $(100 \mathrm{U} / \mathrm{ml}$ of penicillin and $100 \mu \mathrm{g} /$ $\mathrm{ml}$ streptomycin). RAW264.7 cells $\left(2 \times 10^{6}\right.$ cells $\left./ \mathrm{ml}\right)$ were incubated at $37^{\circ} \mathrm{C}$ in a $5 \% \mathrm{CO}_{2}$, humidified incubator (Heraeus BB15, Thermo Fisher Scientific, Waltham, MA, USA). For experiments, RAW264.7 cells were detached from the plate with a cell scraper.

2.5. NO and PGE 2 Production Assay. LPS, pam3CSK4, and poly(I:C) were added to RAW264.7 cells or peritoneal macrophages and incubated for $24 \mathrm{~h}$ after a $30 \mathrm{~min}$ Pa-ME pretreatment. $100 \mu \mathrm{l}$ of supernatant was obtained and mixed with $100 \mu \mathrm{l}$ of Griess reagent, as reported previously [14]. The absorbance of this mixture was measured at $540 \mathrm{~nm}$. The concentration of NO was calculated using an NO standard. L-NAME was used as a positive control. The effect of Pa-ME on $\mathrm{PGE}_{2}$ production was determined by EIAs, as described previously [15].

2.6. Cell Viability Assay. Pa-ME was added to testing cells (HEK293 cells, peritoneal macrophages, and RAW264.7 cells) and incubated for $24 \mathrm{~h}$. Then, $10 \mu \mathrm{l}$ MTT solution $(10 \mathrm{mg} / \mathrm{ml}$ in PBS pH 7.4) was added and incubated for $3 \mathrm{~h}$ as reported previously [16]. The reaction was stopped by $15 \%$ sodium dodecyl sulphate and the samples were incubated for another $24 \mathrm{~h}$. The percentage of living cells relative to the control was calculated by using absorbance at $570 \mathrm{~nm}$.

2.7. High-Performance Liquid Chromatography (HPLC). High-performance liquid chromatography (HPLC) analysis was utilized for confirmation of the phytochemical characteristics of $\mathrm{Pa}-\mathrm{ME}$ with the standard compounds quercetin, luteolin, and kaempferol [17]. The analysis used a system equipped with a KNAUER (Wellchrom) HPLC-pump K1001, a Wellchrom fast scanning spectrophotometer K-2600, and a 4-channel degasser K-500. Elution solvents were solvent $\mathrm{A}\left(0.1 \% \mathrm{H}_{3} \mathrm{PO}_{4}\right.$ in $\left.\mathrm{H}_{2} \mathrm{O}\right)$ and solvent $\mathrm{B}$ (acetonitrile). The gradient step of the solvent was solvent $\mathrm{A}$ to solvent $\mathrm{B} / \mathrm{min}$, and a Phenomenex Gemini $\mathrm{C}_{18}$ ODS $(5 \mu \mathrm{m})$ column was used.

2.8. Measurement of $m R N A$ Expression Levels by ReverseTranscriptase Polymerase Chain Reaction (RT-PCR). To measure the expression level of mRNA related to inflammatory signaling, RT-PCR was conducted. RAW264.7 cells were 
TABLE 1: Sequences of primers used for semiquantitative reversetranscription PCR in this study.

\begin{tabular}{lc}
\hline Targets & Sequences $\left(5^{\prime}\right.$ to $\left.3^{\prime}\right)$ \\
\hline iNOS & \\
Forward & GGAGCCTTTAGACCTCAACAGA \\
Reverse & TGAACGAGGAGGGTGGTG \\
COX-2 & \\
Forward & GGGAGTCTGGAACATTGTGAA \\
Reverse & GCACATTGTAAGTAGGTGGACTGT \\
GAPDH & \\
Forward & GCACATTGTAAGTAGGTGGACTGT \\
Reverse & AGGGAGATGCTCAGTGTTGG \\
\hline
\end{tabular}

incubated for $6 \mathrm{~h}$ with LPS $(1 \mu \mathrm{g} / \mathrm{ml})$ after $30 \mathrm{~min}$ of Pa-ME pretreatment. Total RNA was obtained using TRIzol reagent (Gibco BRL) according to the manufacturer's instructions. Total mRNA was frozen at $-70^{\circ} \mathrm{C}$ for future use. First, $1 \mu \mathrm{g}$ of RNA was incubated at $70^{\circ} \mathrm{C}$ with oligo-dT for 5 minutes. After that, it was incubated for 5 more minutes after mixing with $5 \mathrm{x}$ first-strand buffer, $10 \mathrm{mM}$ dNTPs, and $0.1 \mathrm{M}$ dithiothreitol (DTT). Then, we added MuLV reverse-transcriptase (2 U) and incubated the mixture at $37^{\circ} \mathrm{C}$ for $60 \mathrm{~min}$ and $70^{\circ} \mathrm{C}$ for 10 minutes. The remaining RNAs were removed by RNase $\mathrm{H}$. The polymerase chain reaction (PCR) was conducted with the incubation mixture $\left(2 \mu \mathrm{l} \mathrm{cDNA}, 1 \mu \mathrm{l} 5^{\prime}\right.$ primer, $1 \mu \mathrm{l} 3^{\prime}$ primer, and $6 \mu \mathrm{l}$ diethyl pyrocarbonate (DEPC)) in a $10 \mu \mathrm{l}$ premix using the RT-thermal cycler (Bio-Rad, Hercules, CA, USA). The primer (Bioneer, Daejeon, Republic of Korea) sequence is listed in Table 1. Amplified cDNA was loaded onto a $1.5 \%$ agarose gel with TAE buffer with $0.5 \mu \mathrm{g} / \mathrm{ml}$ ethidium bromide $(\mathrm{EtBr})$ and run at $100 \mathrm{~V}$ for $1 \mathrm{~h}$. The relative quantities were visualized with the DNR Bio-imaging system (Jerusalem, Israel).

2.9. Preparation of Nuclear/Total Lysates of Cells. RAW264.7 cells were washed with cold PBS containing $1 \mathrm{mM}$ sodium orthovanadate and lysed using a sonicator (Thermo Fisher Scientific, Waltham, MA, USA) in ice-cold modified RIPA buffer (50 mM Tris- $\mathrm{HCl}$ (pH 7.4), 1\% Nonidet P-40, 0.25\% sodium deoxycholate, $150 \mathrm{mM} \mathrm{NaCl}, 1 \mathrm{mM} \mathrm{Na} \mathrm{VO}_{4}$, and $1 \mathrm{mM} \mathrm{NaF}$ ) containing protease inhibitors (2 mM PMSF, $100 \mu \mathrm{g} / \mathrm{ml}$ leupeptin, $10 \mu \mathrm{g} / \mathrm{ml}$ pepstatin, $1 \mu \mathrm{g} / \mathrm{ml}$ aprotinin, and $2 \mathrm{mM}$ EDTA) for $30 \mathrm{~min}$ with rotation at $4^{\circ} \mathrm{C}$. Lysates were refined by centrifugation at $16,000 \times \mathrm{g}$ for 10 minutes at $4^{\circ} \mathrm{C}$ and stored at $-20^{\circ} \mathrm{C}$ until use. Nuclear fractions were prepared in a three-step procedure. First, after treatment with $\mathrm{Pa}-\mathrm{ME}$, we collected cells with a rubber policeman and lysed them with $500 \mathrm{ml}$ lysis buffer $(50 \mathrm{mM} \mathrm{KCl}, 0.5 \%$ Nonidet P-40, $25 \mathrm{mM}$ HEPES, $1 \mathrm{mM}$ phenylmethylsulfonyl fluoride, $10 \mu \mathrm{g} / \mathrm{ml}$ leupeptin, $20 \mu \mathrm{g} / \mathrm{ml}$ aprotinin, and $100 \mu \mathrm{M}$ 1,4-dithiothreitol) on ice for $4 \mathrm{~min}$. Lysates were centrifuged at $16000 \times \mathrm{g}$ for $1 \mathrm{~min}$. Second, the pellet was washed with the washing buffer (lysis buffer without Nonidet P-40). Finally, we incubated the nuclei with extraction buffer (lysis buffer with $500 \mathrm{mM} \mathrm{KCl}$ and $10 \%$ glycerol), froze the nuclei/extraction buffer mixture at $-80^{\circ} \mathrm{C}$, and centrifuged the mixture at $16000 \times \mathrm{g}$ for 5 minutes. The supernatant was collected as a nuclear extract. Soluble cell lysates ( $30 \mu \mathrm{g} / \mathrm{lane})$ were immunoblotted.

2.10. Detection of Proteins by Western Blot Analysis. The phosphorylated or total levels of p65, p50, c-Jun, c-Fos, Lamin A/C, I $\kappa \mathrm{B} \alpha, \mathrm{IKK} \alpha / \beta, \mathrm{AKT}, \mathrm{Src}$, Syk, ERK, p85, p38, JNK, IRAK1, IRAK4, TAK1, MKK3, MKK3/6, and $\beta$-actin were visualized by Western blotting. Nuclear and whole cell extracts containing protein were subjected to $7-15 \%$ sodium sulphate polyacrylamide gel electrophoresis (SDSPAGE). Then, the gel was transferred onto a polyvinylidene difluoride (PVDF) membrane and blocked using BSA. The membrane was rotated overnight with the first antibody in BSA. It was washed with Tris-buffered saline with Tween 20 (TBST) and then probed with a second antibody conjugated with horseradish peroxidase in BSA for $1 \mathrm{~h}$. Using an enhanced chemiluminescence kit (Pierce ECL Western blotting substrate, Thermo Scientific, Waltham, MA, USA), immunoreactive bands were detected.

2.11. Immunoprecipitation. Cell lysates containing equal amounts of protein $(500 \mu \mathrm{g})$ from RAW 264.7 cells $(1 \times$ $10^{7}$ cells $\left./ \mathrm{ml}\right)$ treated with or without LPS $(1 \mu \mathrm{g} / \mathrm{ml})$ for $3 \mathrm{~min}$ were precleared with $10 \mu \mathrm{l}$ protein A-coupled Sepharose beads $(50 \% \mathrm{v} / \mathrm{v})$ (Amersham, UK) for $1 \mathrm{~h}$ at $4^{\circ} \mathrm{C}$, as reported previously [18]. Then, the samples were incubated with $5 \mu \mathrm{l}$ antibodies to Syk, Src, or TAK1 overnight at $4^{\circ} \mathrm{C}$. The antigen-antibody complexes were mixed with $10 \mu \mathrm{l}$ protein A-coupled Sepharose beads $(50 \% \mathrm{v} / \mathrm{v})$ and rotated for $3 \mathrm{~h}$ at $4^{\circ} \mathrm{C}$. After that, the immunoprecipitates were analyzed by immunoblotting analysis.

2.12. Plasmid Transfection and Luciferase Reporter Assay. HEK293T cells $\left(1 \times 10^{6}\right.$ cells $\left./ \mathrm{ml}\right)$ were transfected with $1 \mu \mathrm{g}$ of HA-TAK1 alone or plasmids containing $\beta$-galactosidase $(\beta$ Gal) (as a control) and AP-1-Luc in the presence or absence of an inducing molecule, TAK1. Transfections were performed using the PEI method in 6-well plates, as previously outlined $[19,20]$. Transfected cells were used at $48 \mathrm{~h}$ after transfection for all experiments. Cells were treated with $\mathrm{Pa}-\mathrm{ME}$ for the final $24 \mathrm{~h}$ of each experiment. Luciferase assays were performed using the Luciferase Assay System (Promega), as previously reported [21].

2.13. Statistical Analysis. Data presented herein are the mean $\pm \mathrm{SD}$ of in vitro experiments performed with two samples (Figures 1(a) and 1(b)). For statistical comparisons, results were analyzed using analysis of variance/Scheffe's post hoc test and the Kruskal-Wallis/Mann-Whitney test. A $P$ value < 0.05 was considered statistically significant. All statistical tests were carried out using SPSS software (SPSS Inc., Chicago, IL, USA).

\section{Results}

3.1. Pa-ME Suppressed the Production of NO. Since NO is a representative mediator of inflammation, we examined whether Pa-ME was able to suppress inflammatory responses 

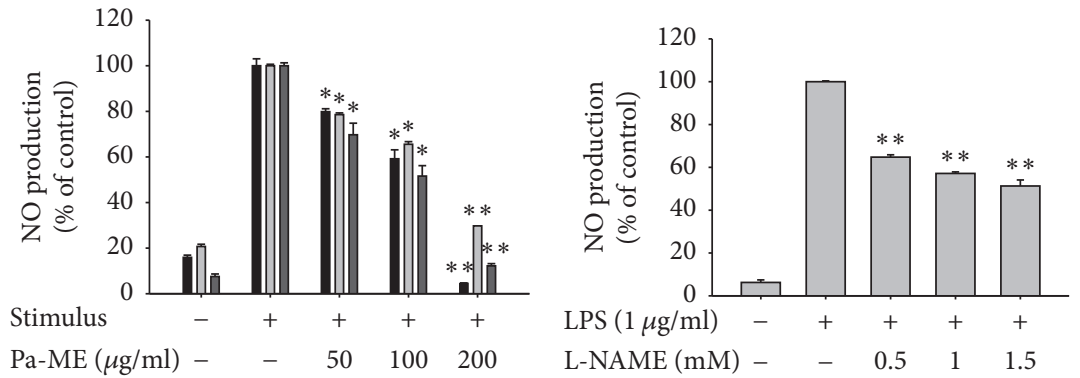

$$
\begin{aligned}
& \operatorname{Pa}-\mathrm{ME}(\mu \mathrm{g} / \mathrm{ml})-\quad-\quad \begin{array}{cccc}
50 & 100 & 200
\end{array} \\
& \begin{array}{l}
\text { LPS }(1 \mu \mathrm{g} / \mathrm{ml}) \\
\text { Pam3CSK4 }(10 \mu \mathrm{g} / \mathrm{ml}) \\
\text { Poly I: C }(200 \mu \mathrm{g} / \mathrm{ml})
\end{array}
\end{aligned}
$$

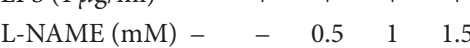

(a)
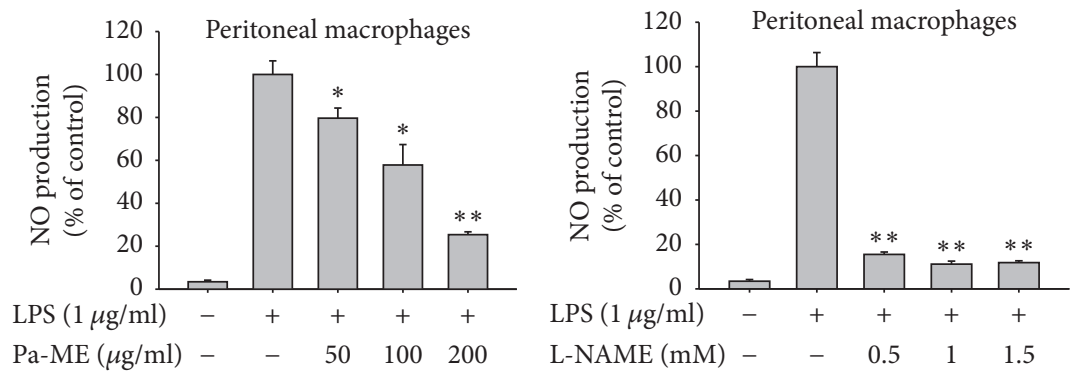

(b)
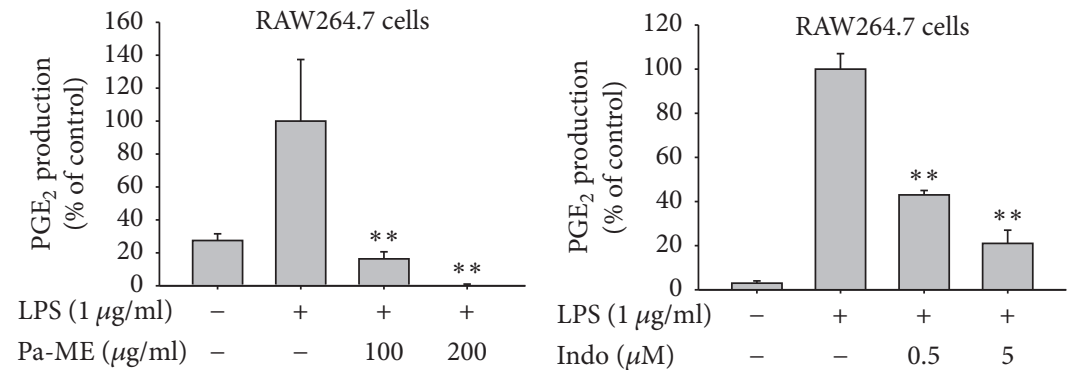

(c)
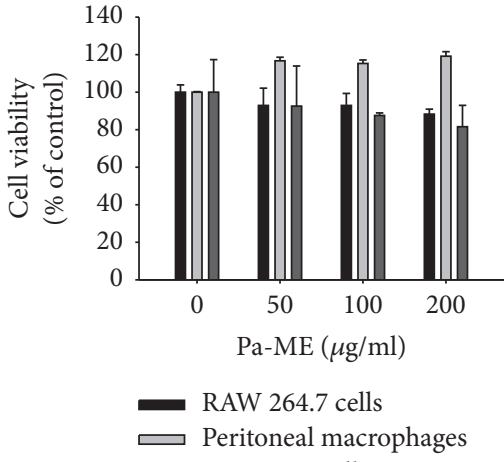

HEK293T cells

(d)

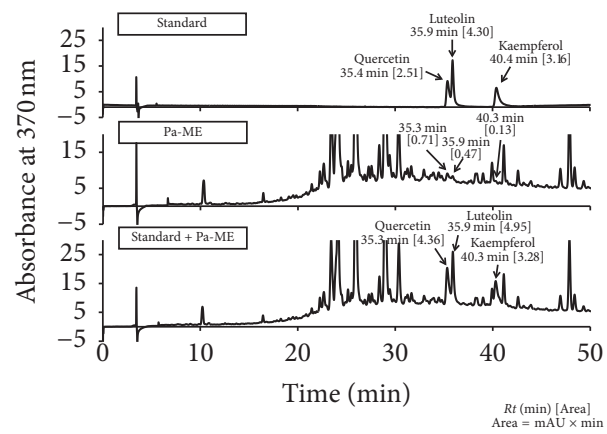

(e)

Figure 1: Effect of Pa-ME on NO production and cell viability. (a, b, and c) Cells were pretreated with Pa-ME or standard compounds [Indo (indomethacin) and L-NAME] and incubated for $24 \mathrm{~h}$ with TLR ligands (LPS, pam3CSK4, and poly(I:C)). The levels of NO (a and b) and $\mathrm{PGE}_{2}$ (c) were analyzed by Griess assay or EIA from the culture supernatant of RAW264.7 cells (a and c) or peritoneal macrophages (b) which were stimulated by LPS $(1 \mu \mathrm{g} / \mathrm{ml})$, poly(I:C) $(200 \mu \mathrm{g} / \mathrm{ml})$, and pam3CSK4 $(10 \mu \mathrm{g} / \mathrm{ml})$ (right panel) in the presence or absence of Pa-ME or L-NAME. (d) Viability of RAW264.7 cells (left panel) or peritoneal macrophages (right panel) was determined by MTT assay. (e) The phytochemical profile of Pa-ME was analyzed by HPLC with standard flavonoids, quercetin, luteolin, and kaempferol [Area]. ${ }^{*} P<0.05$ and ${ }^{* *} P<0.01$ compared with control group. 


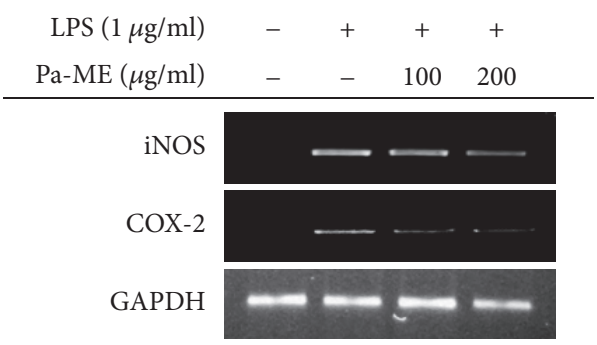

(a)

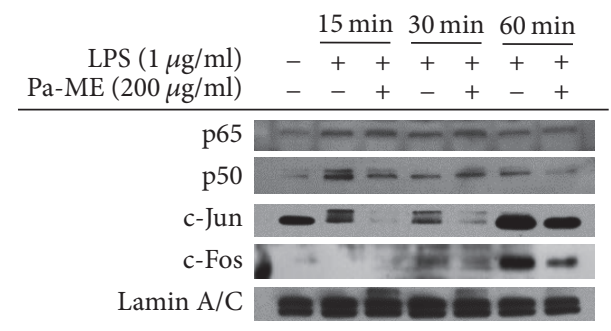

(b)

FIGURE 2: Effect of Pa-ME on the transcriptional activation of proinflammatory genes. (a) Levels of iNOS, COX-2, and GAPDH mRNA were determined by semiquantitative PCR. (b) Nuclear levels of NF- $\kappa$ B (p65 and p50), AP-1 (c-Jun and c-Fos), and Lamin A/C in nuclear fractions were determined by nuclear fractionation and immunoblotting analysis.

TABLE 2: The estimated content of anti-inflammatory flavonoids in Pa-ME.

\begin{tabular}{lcc}
\hline Flavonoid & \multicolumn{2}{c}{ Content } \\
& $\mathrm{mg} / \mathrm{g}$ & $\%$ \\
\hline Quercetin & 0.038 & 0.004 \\
Luteolin & 0.010 & 0.001 \\
Kaempferol & 0.015 & 0.001 \\
\hline
\end{tabular}

by determining NO levels in culture supernatant prepared from activated RAW264.7 cells in the presence or absence of Pa-ME (0 to $200 \mu \mathrm{g} / \mathrm{ml}$ ). As Figure 1(a) shows, the amount of NO was enhanced via treatment with inflammation inducers (LPS, pam3CSK4, and poly(I:C)) and was dosedependently decreased by Pa-ME (left panel), as in the case of the standard NO inhibitor, L-NAME (right panel). Dosedependent NO inhibition by Pa-ME and L-NAME in a cancerous macrophage cell line was also exhibited in primary cells (peritoneal macrophages) (Figure 1(b)). Moreover, this extract (100 and $200 \mu \mathrm{g} / \mathrm{ml}$ ) downregulated the release of $\mathrm{PGE}_{2}$ as shown in the case of COX inhibitor, indomethacin (Figure 1(c)). Viability measurement of RAW264.7 cells, HEK293 cells, and peritoneal macrophages (right panel) treated with $\mathrm{Pa}-\mathrm{ME}$ revealed that $\mathrm{Pa}-\mathrm{ME}$ inhibition of $\mathrm{NO}$ was not due to nonspecific suppression of cell viability (Figure 1(d)). Meanwhile, to check the phytochemical profile of $\mathrm{Pa}-\mathrm{ME}$, we performed high-performance liquid chromatography (HPLC) analysis of Pa-ME with flavonoids such as quercetin, luteolin, and kaempferol, which are known to inhibit NO release $[18,22]$. As Figure 1(e) and Table 2 show, quercetin, luteolin, and kaempferol were detected at 35.3, 35.9 , and $40.3 \mathrm{~min}$ at $0.004,0.001$, and $0.001 \%$, respectively.

3.2. Pa-ME Suppressed Inflammatory Gene Expression and Nuclear Translocation of NF- $\kappa B$ and AP-1. The effect of Pa$\mathrm{ME}$ on inflammatory gene expression was examined by analysis of iNOS and COX-2 mRNA levels by reversetranscription polymerase chain reaction. As Figure 2(a) depicts, the quantity of iNOS and COX-2 was dosedependently reduced by $\mathrm{Pa}-\mathrm{ME}$. To confirm whether this extract was capable of modulating the activation of transcription factors, the nuclear translocation levels of NF- $\kappa \mathrm{B}$ and AP-1 were detected by Western blotting with nuclear fractions. As Figure 2(b) indicates, the nuclear level of p50/NF$\kappa \mathrm{B}$ was reduced by $\mathrm{Pa}-\mathrm{ME}$ at 15 and $60 \mathrm{~min}$ of LPS treatment. In addition, c-Jun and c-Fos, major AP-1 subunits, were also suppressed by Pa-ME at 15, 30, and $60 \mathrm{~min}$ (Figure 2(b)).

3.3. Pa-ME Suppresses Upstream Proteins in NF- $\kappa B$ Signaling Pathway. To verify the immunopharmacological targets of $\mathrm{Pa}-\mathrm{ME}$, we elucidated the upstream signaling molecules that were involved in the NF- $\kappa \mathrm{B}$ signaling pathway immunoblotting analysis. Interestingly, the phosphorylated forms of $\mathrm{I} \kappa \mathrm{B} \alpha, \mathrm{IKK} \alpha / \beta$, and $\mathrm{AKT}$ were reduced by $\mathrm{Pa}-\mathrm{ME}$ at 30 and 60 min after LPS treatment, while their total forms remained constant (Figure 3(a)). Moreover, the phosphorylation levels of the upstream protein tyrosine kinases, Src and Syk, were also decreased at 2, 3, and $5 \mathrm{~min}$ without alteration of their total levels (Figure 3(b)). To ensure that these proteins could be targeted by $\mathrm{Pa}-\mathrm{ME}$, we further conducted immunoprecipitation analysis to measure the binding levels of p-p85, an active substrate of Src, Syk, and p85. The binding level of phospho-p85 was clearly reduced in the immunoprecipitation mixture composed of Syk or Src after treatment with $\mathrm{Pa}-$ ME (Figure 3(c)).

\subsection{Pa-ME Suppresses Upstream Proteins in the AP-1 Signaling} Pathway. We evaluated whether $\mathrm{Pa}-\mathrm{ME}$ could modulate the AP-1 activation pathway by measuring MAPK protein phosphorylation. As Figure 4(a) shows, the phosphorylation levels of ERK, p38, and JNK1/2 and their upstream enzymes MKK3/6 and TAK1 under LPS stimulation at 2, 3, and 5 min were decreased by Pa-ME (Figure 4(b)). Since TAK1 is upstream of the MAPK/AP-1 pathway, a further validation experiment was carried out by immunoprecipitation analysis. Interestingly, the binding of p-MKK3/6 to TAK1 was clearly reduced by $\mathrm{Pa}-\mathrm{ME}$ treatment (Figure $4(\mathrm{c})$ ). In addition, the luciferase activity induced by TAK1/AP-1 was also dosedependently suppressed by this extract (Figure 4(d)), according to reporter gene assay. Moreover, $\mathrm{Pa}-\mathrm{ME}$ suppressed the phosphorylation of TAK1 triggered under HA-TAK1 overexpression (Figure 4(e)). 


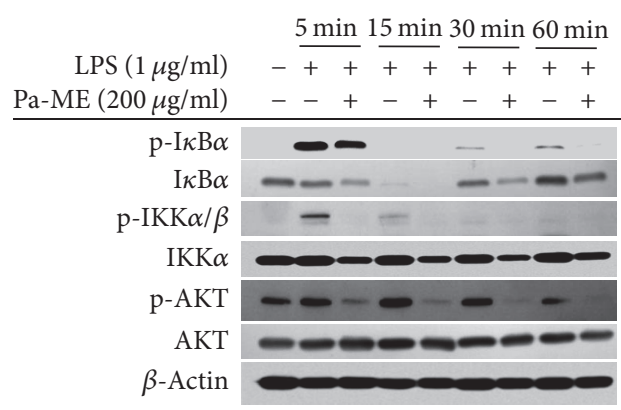

(a)

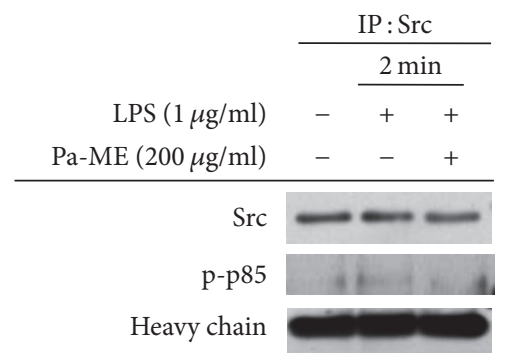

(c)

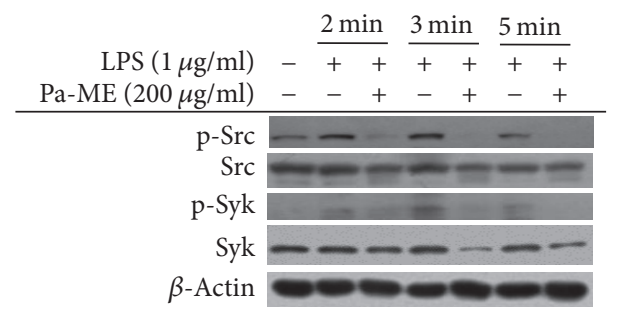

(b)

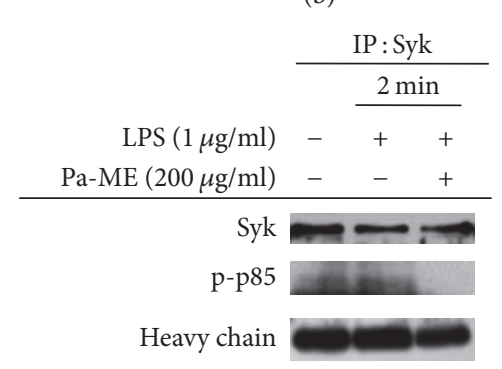

FIGURE 3: Effect of Pa-ME on the activation of upstream signaling molecules for NF- $\kappa$ B translocation. (a and b) Phosphorylated or total forms of $\mathrm{I} \kappa \mathrm{B} \alpha, \mathrm{IKK} \alpha / \beta, \mathrm{AKT}$, Src, Syk, and $\beta$-actin levels at 5, 15, 30, and $60 \mathrm{~min}$ or 2, 3, and 5 min were detected by immunoblotting analysis with phospho-specific or total protein antibodies from total cell lysates. (c) The binding level of p-p85 to Src (left panel) or Syk (right panel) at 2 min was detected by immunoprecipitation and immunoblotting analysis of LPS-treated RAW264.7 cells in the presence or absence of Pa-ME.

\section{Discussion}

NO, which stands for nitric oxide, is secreted as a result of inflammation and is involved in the innate response and cytotoxicity [23]. LPS, pam3CSK4, and poly(I:C) are the ligands of toll-like receptors TLR4, TLR2/TLR1, and TLR3, respectively [24], so they can trigger inflammatory responses. When we measured the amount of NO after Pa-ME pretreatment and treatment with LPS, pam3CSK4, and poly(I:C) in RAW264.7 cells, we found that Pa-ME suppressed NO and $\mathrm{PGE}_{2}$ production in a dose-dependent manner (Figures 1(a) left panel, and 1(c) left panel) with no significant effect on cell viability in the $50-200 \mu \mathrm{g} / \mathrm{ml}$ concentration range (Figure 1(d)). When we changed the cell type into peritoneal macrophages, similar data were produced (Figures 1(b) left panel, and 1(c) right panel). Since Pa-ME and L-NAME have similar effects on the nitric oxide synthase inhibitor, it appears that Pa-ME suppresses NO production. By analyzing the phytochemical properties of Pa-ME with HPLC (Figure 1(e) and Table 2), we identified flavonoids such as quercetin, luteolin, and kaempferol, which were known for their antiinflammatory effects [25-27]. There were peaks corresponding to the retention time of the standard compound, and combined samples with $\mathrm{Pa}-\mathrm{ME}$ and flavonoids enhanced the area proportionally (Figure $1(\mathrm{e})$ ). This ensures that $\mathrm{Pa}-\mathrm{ME}$ can decrease NO production in inflammatory situations.

Under inflammatory conditions, NO is generated by iNOS in macrophages [28]. Various genes in addition to iNOS are used to make cytokines that mediate inflammation. Representative inflammatory mRNA, iNOS, and COX-2 levels were examined in this study, and Pa-ME reduced iNOS and COX-2 (Figure 2(a)). Thus, iNOS and COX-2 were decreased in a dose-dependent manner at 0 to $200 \mu \mathrm{g} / \mathrm{ml}$. Therefore, the ideal concentration of $\mathrm{Pa}-\mathrm{ME}$ for inhibiting inflammation is $200 \mu \mathrm{g} / \mathrm{ml}$, and we used this concentration in experiments afterwards. It is generally known that NF$\kappa \mathrm{B}$ regulates iNOS and AP-1 regulates COX -2 [29]. NF- $\kappa \mathrm{B}$ consists of p65 and p50, while AP-1 consists of c-Fos and c-Jun $[30,31]$. The subunits are merged in the cytosol and translocate into the nucleus. If $\mathrm{Pa}-\mathrm{ME}$ directly regulates gene transcription, the nuclear quantities of p65, p50, c-Fos, and c-Jun should not be decreased. However, immunoblotting of the nuclear lysate showed reduced protein levels of p50, cJun, and c-Fos (Figure 2(b)), implying that Pa-ME affects upstream signals that regulate transcription factors. First, we confirmed the NF- $\kappa \mathrm{B}$ signaling pathway and tried to identify molecules linking to $\mathrm{Pa}-\mathrm{ME}$ pharmacology. In the $\mathrm{NF}-\kappa \mathrm{B}$ signaling pathway, $\mathrm{I} \kappa \mathrm{B} \alpha, \mathrm{IKK} \alpha, \mathrm{IKK} \beta, \mathrm{AKT}, \mathrm{Src}$, and Syk are involved. By Western blotting, we found that the phospho-forms of $\mathrm{I} \kappa \mathrm{B} \alpha, \mathrm{IKK} \alpha / \beta$, and AKT were decreased at 30 and $60 \mathrm{~min}$ (Figure 3(a)). In addition, Src and Syk were reduced at 2,3 , and $5 \mathrm{~min}$, and there were few changes in the total forms of all enzymes (Figure 3(b)). Because there is no enzyme upstream of Src and Syk, these may be $\mathrm{Pa}-\mathrm{ME}$ targets. We further validated this possibility by carrying out immunoprecipitation/immunoblotting analysis and overexpression of these genes. Total Src and Syk did not change with $\mathrm{Pa}-\mathrm{ME}$ treatment, while this extract reduced the p-p85 levels bound in Src or Syk complexes (Figure 3(c)). 


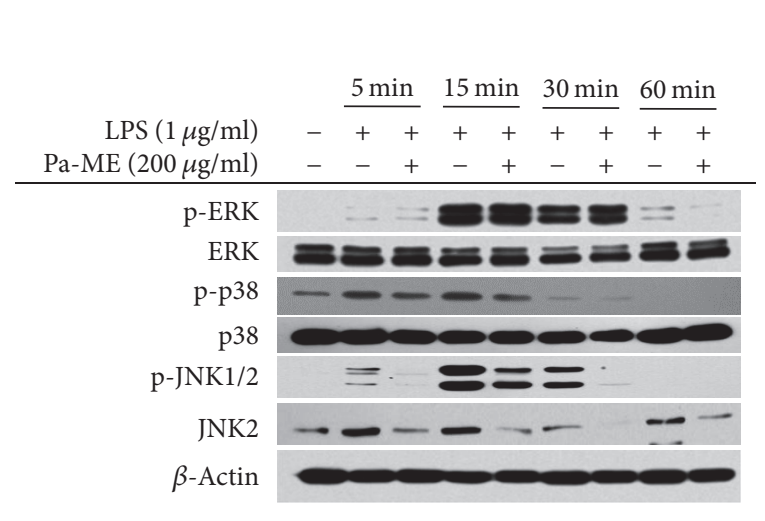

(a)

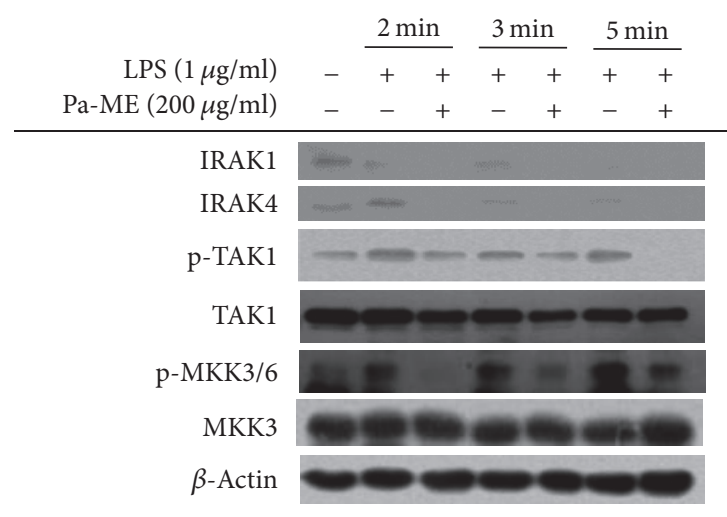

(b)
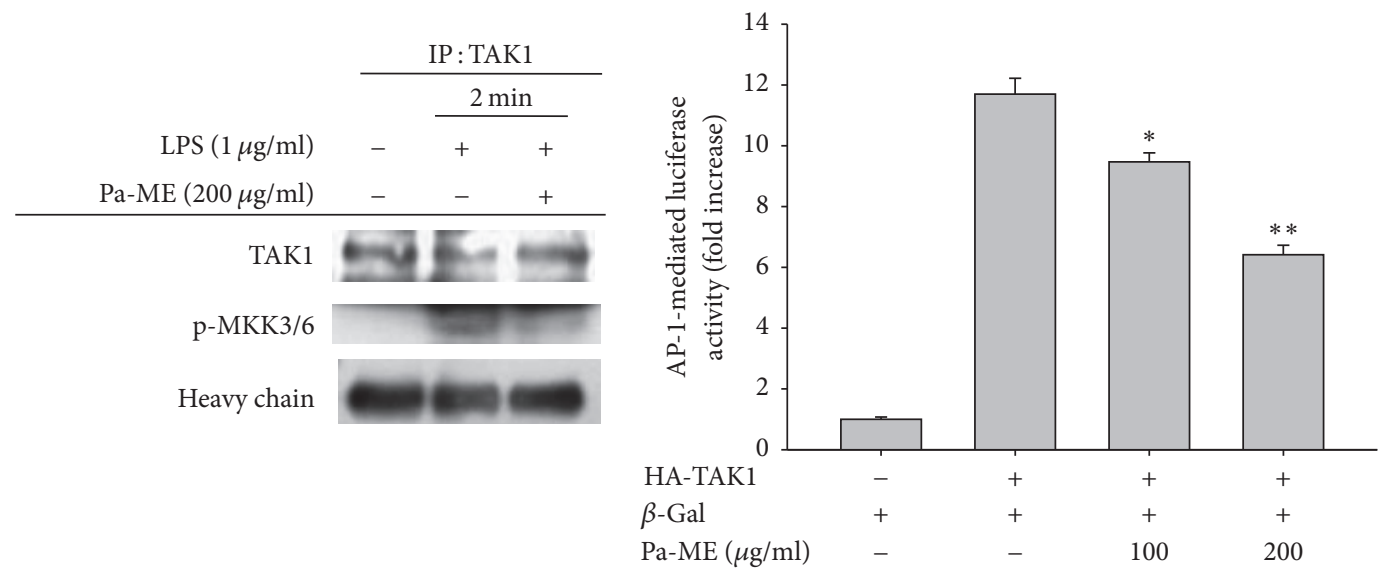

(c)

(d)

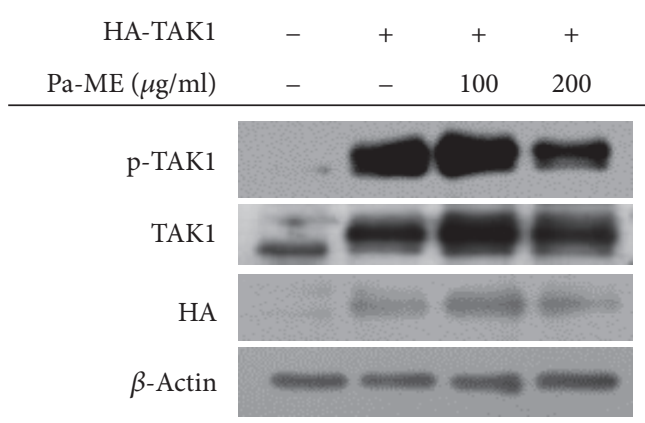

(e)

FIgURE 4: Effects of Pa-ME on the activation of upstream signaling molecules for AP-1 translocation. (a and b) Phosphorylated or total forms of ERK, p38, JNK1/2, IRAK1, IRAK4, TAK1, MKK3/6, MKK3, and $\beta$-actin levels at 5, 15, 30, and 60 min or 2 , 3, and 5 min were detected by immunoblotting analysis with phospho-specific or total protein antibodies from total cell lysates. (c) The binding level of p-MKK3/6 to TAK1 at 2 min was detected by immunoprecipitation and immunoblotting analysis of LPS-treated RAW264.7 cells in the presence or absence of Pa-ME. $\beta$-Gal, $\beta$-galactosidase. ${ }^{*} P<0.05$ and ${ }^{* *} P<0.01$ compared with control group.

Overall, it is likely that $\mathrm{Pa}-\mathrm{ME}$ might target Src and Syk during its anti-inflammatory activity toward the NF- $\kappa \mathrm{B}$ signaling pathway.

We also explored whether Pa-ME could modulate the AP-1 signaling pathway, as the COX-2 mRNA level was decreased (Figure 2(a)). There are three subpathways within the AP-1 signaling pathway which are composed of JNK, p38, and ERK [32]. Interestingly, $\mathrm{Pa}-\mathrm{ME}$ reduced the phosphorylation of all these MAPKs (Figure 4(a)), implying that some common protein(s) might be targeted by this extract. By evaluating common upstream molecules, we identified that TAK1 might be a Pa-ME target for suppression of the AP-1 pathway. Indeed, the binding of p-MKK3/6 to TAK1 was reduced by treatment with this extract (Figure $4(\mathrm{c})$ ). 


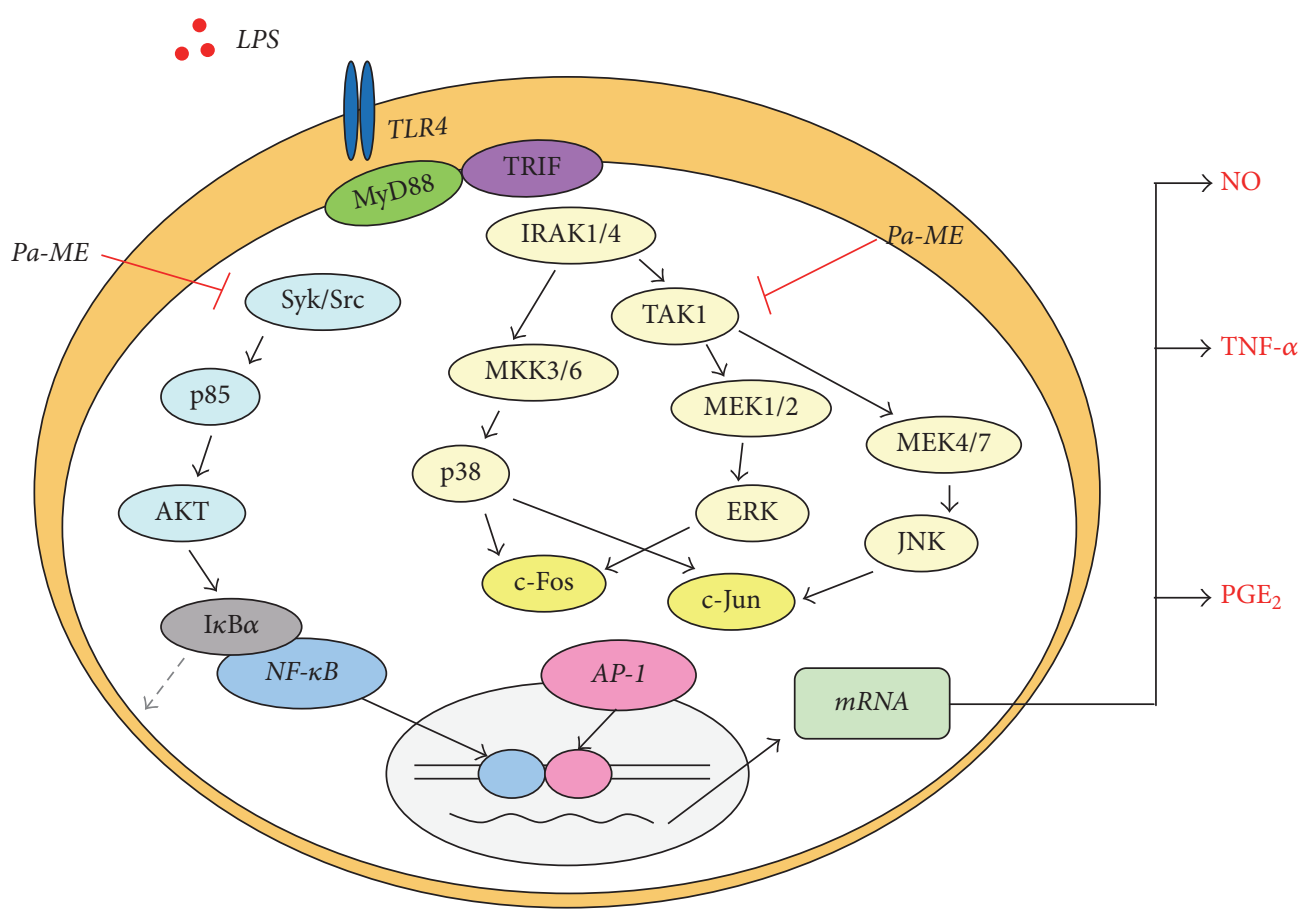

FIGURE 5: Putative inhibitory pathway of Pa-ME-mediated anti-inflammatory responses. Pa-ME suppressed both Syk and Src kinase activity in the NF- $\kappa$ B pathway and TAK1 kinase activity in the AP-1 pathway. Following that, Pa-ME inhibited the activity of downstream molecules, leading to anti-inflammatory effects.

TAK1 overexpression-derived phosphorylation and luciferase activity were also effectively suppressed by Pa-ME (Figures 4(d) and 4(e)). These results therefore seem to suggest that $\mathrm{Pa}-\mathrm{ME}$ also targets the TAK1 enzyme to modulate the AP-1 pathway.

In conclusion, we revealed that $\mathrm{Pa}-\mathrm{ME}$ can relieve inflammation by inhibiting Src, Syk, and TAK1 to suppress both the NF- $\kappa \mathrm{B}$ and AP-1 pathways, as summarized in Figure 5. Although $\mathrm{Pa}-\mathrm{ME}$ was proposed as a potential antiinflammatory remedy, our data clearly provide experimental evidence to support its anti-inflammatory activity. Further preclinical studies on anti-inflammatory action using various in vivo models will be needed to confirm the antiinflammatory properties of this plant for therapeutic use.

\section{Abbreviations}

NO: $\quad$ Nitric oxide

LPS: $\quad$ Lipopolysaccharide

Pam3CSK4: Synthetic bacterial lipopeptide Pam3Cys-Ser-(Lys) 4

Poly(I:C): Polyinosinic:polycytidylic acid

L-NAME: $\quad$ L-N $^{\mathrm{G}}$-nitroarginine methyl ester

MTT: 3-(4,5-Dimethylthiazol-2-yl)-2,5diphenyltetrazolium bromide

HPLC: High-performance liquid chromatography

RT-PCR: Reverse-transcriptase polymerase chain reaction

iNOS: $\quad$ Inducible NO synthase
COX-2: Cyclooxygenase-2

TNF- $\alpha$ : Tumor necrosis factor-alpha

IP: Immunoprecipitation

Src: $\quad$ Nonreceptor tyrosine kinase

Syk: $\quad$ Spleen tyrosine kinase

TAK1: Transforming growth factor beta-kinase 1 .

\section{Disclosure}

The authors alone are responsible for the content and writing of the paper.

\section{Conflicts of Interest}

The authors report no conflicts of interest.

\section{Authors' Contributions}

You Jin Kim, Jeong Deok, and Sunggyu Kim contributed equally to this work.

\section{Acknowledgments}

This work was carried out with the support of BK21 Plus, NRF, Republic of Korea. This work was also supported by Priority Research Centers Program through the National Research Foundation of Korea (NRF) funded by the Ministry of Education, Science and Technology. 


\section{References}

[1] R. Nowarski, N. Gagliani, S. Huber, and R. A. Flavell, "Innate immune cells in inflammation and cancer," Cancer Immunology Research, vol. 1, no. 2, pp. 77-84, 2013.

[2] H.-M. Lee, T. S. Kim, and E.-K. Jo, "MiR-146 and miR-125 in the regulation of innate immunity and inflammation," $B M B$ Reports, vol. 49, no. 6, pp. 311-318, 2016.

[3] R. Gautam and S. M. Jachak, "Recent developments in antiinflammatory natural products," Medicinal Research Reviews, vol. 29, no. 5, pp. 767-820, 2009.

[4] K. Ren, C. Jin, P. Ma, Q. Ren, Z. Jia, and D. Zhu, "Ginsenoside $\mathrm{Rd}$ alleviates mouse acute renal ischemia/reperfusion injury by modulating macrophage phenotype," Journal of Ginseng Research, 2015.

[5] M. Gaestel, A. Kotlyarov, and M. Kracht, "Targeting innate immunity protein kinase signalling in inflammation," Nature Reviews Drug Discovery, vol. 8, no. 6, pp. 480-499, 2009.

[6] J. H. Kim, M.-Y. Kim, J.-H. Kim, and J. Y. Cho, "Fisetin suppresses macrophage-mediated inflammatory responses by blockade of Src and Syk," Biomolecules and Therapeutics, vol. 23, no. 5, pp. 414-420, 2015.

[7] S. Yang, Y. Kim, D. Jeong et al., "Pyrrole-derivative of chalcone, (E)-3-phenyl-1-(2-pyrrolyl)-2-propenone, inhibits inflammatory responses via inhibition of src, syk, and TAK1 kinase activities," Biomolecules and Therapeutics, vol. 24, no. 6, pp. 595603, 2016.

[8] S.-J. Kim, J.-Y. Cha, H. S. Kang et al., "Corosolic acid ameliorates acute inflammation through inhibition of IRAK-1 phosphorylation in macrophages," BMB Reports, vol. 49, no. 5, pp. 276-281, 2016.

[9] C. P. Khare, Indian Medicinal Plants: An Illustrated Dictionary, Springer Science \& Business Media, 2008.

[10] R. Perumal Samy, S. Ignacimuthu, and A. Sen, "Screening of 34 Indian medicinal plants for antibacterial properties," Journal of Ethnopharmacology, vol. 62, no. 2, pp. 173-181, 1998.

[11] R. Ohlyan, A. Kandale, G. S. Deora, V. Rathore, and J. Chahal, "In vitro screening of dry fruit extracts of Piper attenuatum for antioxidant and anticancer activity," Medicinal Chemistry Research, vol. 22, no. 3, pp. 1365-1370, 2013.

[12] S. Divya Reddy, B. Siva, B. Poornima et al., "New free radical scavenging neolignans from fruits of Piper attenuatum," Pharmacognosy Magazine, vol. 11, no. 42, pp. 235-241, 2015.

[13] V. Kumar, Poonam, A. K. Prasad, and V. S. Parmar, "Naturally occurring aristolactams, aristolochic acids and dioxoaporphines and their biological activities," Natural Product Reports, vol. 20, no. 6, pp. 565-583, 2003.

[14] K.-S. Baek, Y.-S. Yi, Y.-J. Son et al., "In vitro and in vivo antiinflammatory activities of Korean red Ginseng-derived components," Journal of Ginseng Research, vol. 40, no. 4, pp. 437-444, 2016.

[15] Y.-S. Yi, J. Y. Cho, and D. Kim, "Cerbera manghas methanol extract exerts anti-inflammatory activity by targeting c-Jun Nterminal kinase in the AP-1 pathway," Journal of Ethnopharmacology, vol. 193, pp. 387-396, 2016.

[16] K.-S. Baek, Y. D. Hong, Y. Kim et al., "Anti-inflammatory activity of AP-SF, a ginsenoside-enriched fraction, from Korean ginseng," Journal of Ginseng Research, vol. 39, no. 2, pp. 155-161, 2015.

[17] L. Almela, B. Sánchez-Muñoz, J. A. Fernández-López, M. J. Roca, and V. Rabe, "Liquid chromatograpic-mass spectrometric analysis of phenolics and free radical scavenging activity of rosemary extract from different raw material," Journal of Chromatography A, vol. 1120, no. 1-2, pp. 221-229, 2006.

[18] S. H. Kim, J. G. Park, Y. D. Hong et al., "Src/Syk/IRAK1-targeted anti-inflammatory action of Torreya nucifera butanol fraction in lipopolysaccharide-activated RAW264.7 cells," Journal of Ethnopharmacology, vol. 188, pp. 167-176, 2016.

[19] M. J. Hossen, M.-Y. Kim, and J. Y. Cho, "MAPK/AP-1-targeted anti-inflammatory activities of Xanthium strumarium," American Journal of Chinese Medicine, vol. 44, no. 6, pp. 1111-1125, 2016.

[20] Y. Yang, J. Lee, M. H. Rhee et al., "Molecular mechanism of protopanaxadiol saponin fraction-mediated anti-inflammatory actions," Journal of Ginseng Research, vol. 39, no. 1, pp. 61-68, 2015.

[21] N. Y. Sung, M.-Y. Kim, and J. Y. Cho, "Scutellarein reduces inflammatory responses by inhibiting Src kinase activity," Korean Journal of Physiology and Pharmacology, vol. 19, no. 5, pp. 441-449, 2015.

[22] J. O. Lee, D. Jeong, M. Y. Kim, and J. Y. Cho, "ATP-binding pocket-targeted suppression of Src and Syk by luteolin contributes to its anti-inflammatory action," Mediators of Inflammation, vol. 2015, Article ID 967053, 12 pages, 2015.

[23] P. A. Brennan, I. P. Downie, J. D. Langdon, and G. A. Zaki, "Emerging role of nitric oxide in cancer," British Journal of Oral and Maxillofacial Surgery, vol. 37, no. 5, pp. 370-373, 1999.

[24] F. Schmitz, J. Mages, A. Heit, R. Lang, and H. Wagner, "Transcriptional activation induced in macrophages by Toll-like receptor (TLR) ligands: from expression profiling to a model of TLR signaling," European Journal of Immunology, vol. 34, no. 10, pp. 2863-2873, 2004.

[25] Y. Li, J. Yao, C. Han et al., "Quercetin, inflammation and immunity," Nutrients, vol. 8, no. 3, article no. 167, 2016.

[26] M. Hämäläinen, R. Nieminen, P. Vuorela, M. Heinonen, and E. Moilanen, "Anti-inflammatory effects of flavonoids: genistein, kaempferol, quercetin, and daidzein inhibit STAT-1 and NF$\kappa \mathrm{B}$ activations, whereas flavone, isorhamnetin, naringenin, and pelargonidin inhibit only NF- $\kappa \mathrm{B}$ activation along with their inhibitory effect on iNOS expression and NO production in activated macrophages," Mediators of Inflammation, vol. 2007, Article ID 45673, 10 pages, 2007.

[27] C.-W. Liu, H.-W. Lin, D.-J. Yang et al., "Luteolin inhibits viral-induced inflammatory response in RAW264.7 cells via suppression of STAT1/3 dependent NF- $\kappa$ B and activation of HO-1," Free Radical Biology and Medicine, vol. 95, pp. 180-189, 2016.

[28] B. L. Fiebich, K. Lieb, S. Engels, and M. Heinrich, "Inhibition of LPS-induced p42/44 MAP kinase activation and iNOS/NO synthesis by parthenolide in rat primary microglial cells," Journal of Neuroimmunology, vol. 132, no. 1-2, pp. 18-24, 2002.

[29] W.-J. Oh, U. Jung, H.-S. Eom, H.-J. Shin, and H.-R. Park, "Inhibition of lipopolysaccharide-induced proinflammatory responses by Buddleja officinalis extract in BV-2 microglial cells via negative regulation of NF- $\kappa \mathrm{B}$ and ERK1/2 signaling," Molecules, vol. 18, no. 8, pp. 9195-9206, 2013.

[30] C. Kretz-Remy, P. Mehlen, M.-E. Mirault, and A.-P. Arrigo, "Inhibition of $\mathrm{I} \kappa \mathrm{B}-\alpha$ phosphorylation and degradation and subsequent NF- $\kappa$ B activation by glutathione peroxidase overexpression," Journal of Cell Biology, vol. 133, no. 5, pp. 1083-1093, 1996.

[31] C. Jonat, H. J. Rahmsdorf, K.-K. Park et al., "Antitumor promotion and antiinflammation: Down-modulation of AP-1 
(Fos/Jun) activity by glucocorticoid hormone," Cell, vol. 62, no. 6, pp. 1189-1204, 1990.

[32] Y. Yang, S. C. Kim, T. Yu et al., "Functional roles of p38 mitogenactivated protein kinase in macrophage-mediated inflammatory responses," Mediators of Inflammation, vol. 2014, Article ID 352371, 13 pages, 2014. 


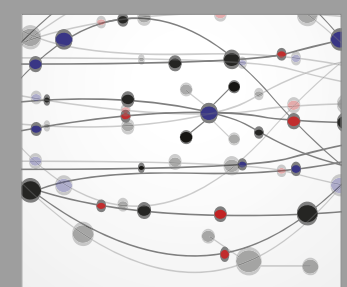

The Scientific World Journal
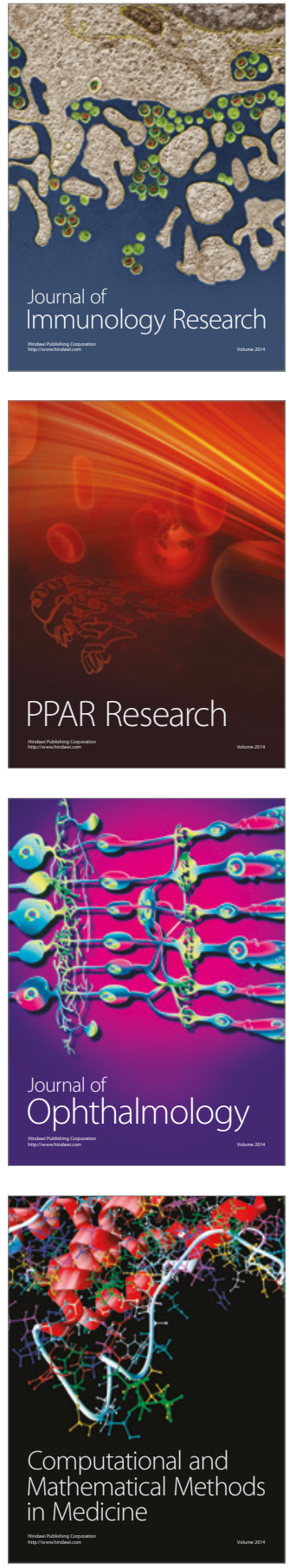

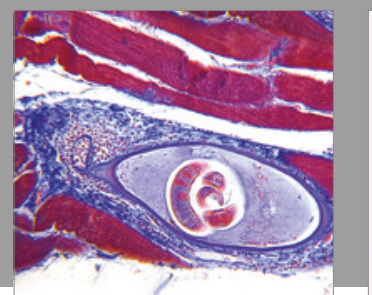

Gastroenterology Research and Practice
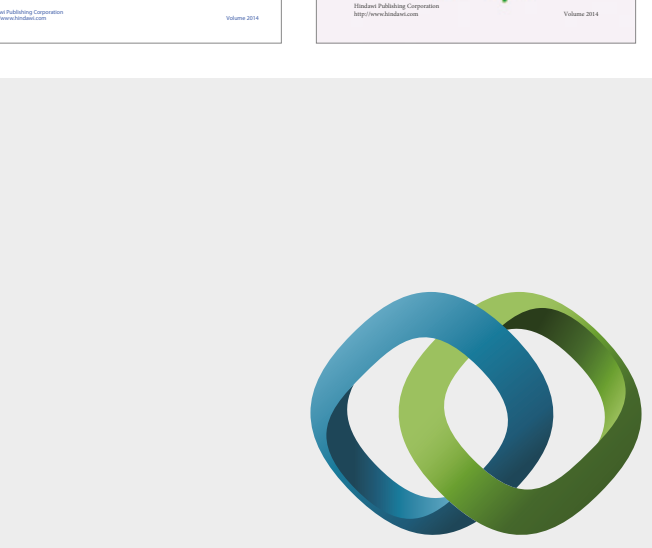

\section{Hindawi}

Submit your manuscripts at

https://www.hindawi.com
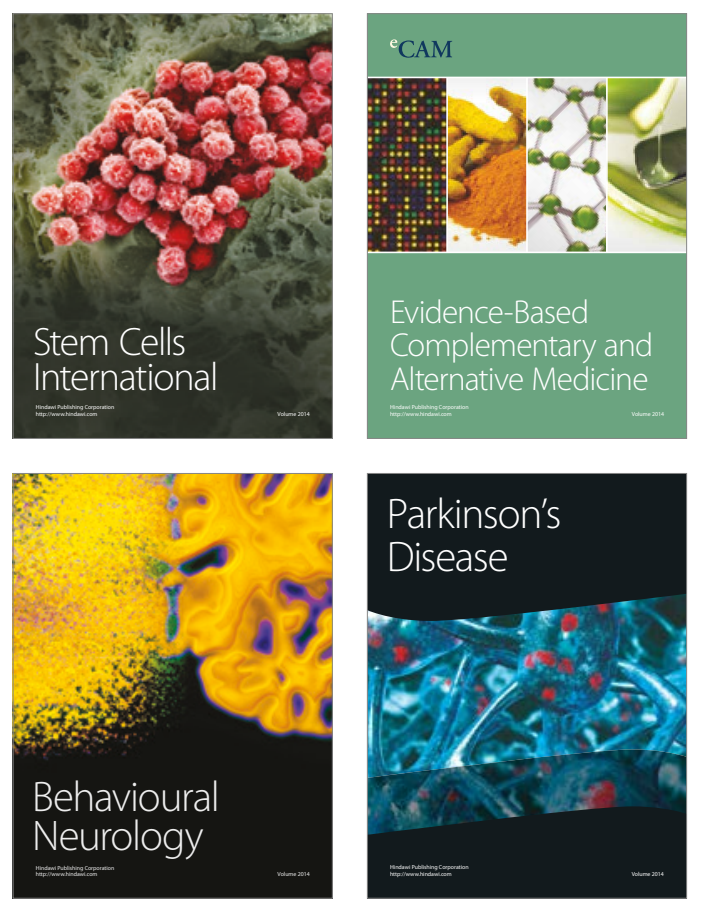
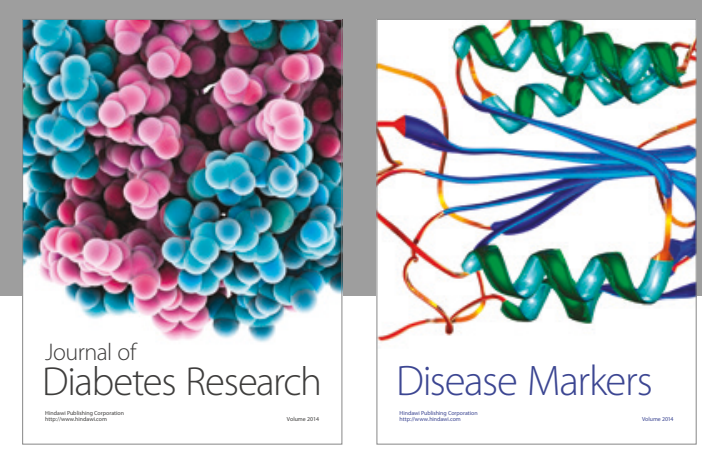

Disease Markers
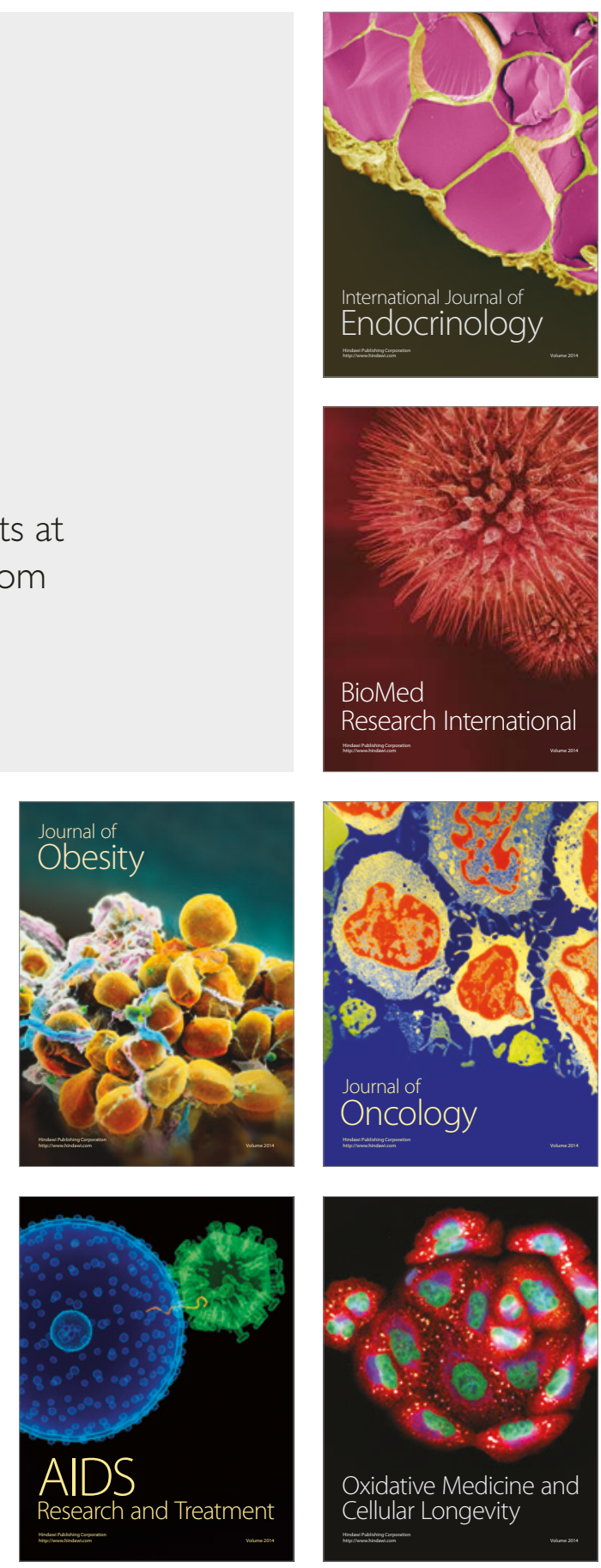